\title{
Teachers' choice of using practical activities - a hierarchical classification attempt
}

\author{
Frode Olav Haara ${ }^{1}$ \\ ${ }^{1}$ Faculty of teacher education and sports, Sogn og Fjordane University College, Sogndal, Norway \\ For correspondence: frode.olav.haara@hisf.no
}

\begin{abstract}
From a system theoretically grounded point of view, a hierarchy of primary and secondary impact factors influencing the mathematics teacher's choice to use practical activities in mathematics teaching is suggested initially in the article. A study, based on qualitative responses from mathematics teachers, then gives grounds for suggesting that a hierarchy of impact factors regarding the choice to use a practical activity in mathematics teaching must include more than just a binary clustering of primary and secondary impact factors. The teacher's everyday life experience, knowledge of pupils' everyday life experience, and the teacher's conscience are suggested examples of impact factors that might call for the introduction of a new level, as they are primary impact factors that seem to depend on adaptation to responses at the secondary impact factor level. This coincides with demands for strengthening of mathematical literacy in school mathematics and more independence for the teacher when it comes to teaching of mathematics.
\end{abstract}

Keywords: Practical activities, hierarchical classification, impact factor, mathematics teaching

\section{Introduction}

Practical activities, here defined to include all forms of engagement where the pupil uses physical concretes while carrying out the activity at hand (Haara \& Smith, 2009), for visualization, investigation and application of mathematics, are considered integral to school mathematics (OECD; 2013; Haara, 2011). Literature on teaching and learning has for some time illuminated the complexity of influence of teacher qualities and several externally originated elements and circumstances on teaching (e.g. Handal \& Lauvås, 1987; Shulman, 1987), and on teaching of mathematics in particular (Franke, Kazemi \& Battey, 2007; Koehler \& Grouws, 1992). All these influential elements, circumstances and qualities are hereafter referred to as impact factors. Examples of what is comprised by this definition are brought up explicitly later in the article. The influence from such impact factors on the teacher's choice of using a practical activity in the teaching, however, is less explained. For instance, what may make the mathematics teacher choose to make use of a leek to concretize geometrically the algebraic deduction of the area of a circle or the essence of integration? The essence of integration can in fact be concretized by showing how the almost rectangular areas of the rings that make up the cross section of the vegetable, are the area between the curve of the circumference of the circle with a variable radius and the "radiusaxis" (the first-axis). This represents the integration of the circumference of the circle in the interval [0, r] (Haara, 2003; Myklebust, 1994). When the teacher decides to make use of such a concrete aid in a practical activity, the choice is influenced by both impact factors stemming from factors related to the teacher and from sources external to the teacher. An impact factor of the first kind is then for instance the teacher's wish to make the pupils investigate the situation for themselves and to use the investigation as a reference in the algebraic deduction. Impact factors of the latter kind, are for instance expectations from the pupils or teacher colleagues, the textbook or the national curriculum. 
Without discussing the practical applications, learning effects of practical activities or the complexity of origin and development of impact factors, the first aim of this article is to suggest a theoretically grounded hierarchical classification of impact factors that influence the mathematics teacher's priorities when choosing to use a practical activity. The suggestion will make use of Bateson's (1972) classical system theory based approach to learning. Further, the aim is to identify possible discrepancies between the suggested hierarchy of impact factors and the experiences of mathematics teachers. The article also discusses if, and how, any such discrepancies call for an adjustment of the initially suggested hierarchy. The use of practical activities in school, especially the uncritical and unquestioned one, has been criticized (e.g. McNeil, Uttal, Jarvin \& Sternberg, 2009; Kjærnsli, Lie, Olsen, Roe \& Turmo, 2004; Klette, 2003; Moyer, 2001). The results of a comparison of a theoretically grounded hierarchy and experience-based data will have implications at two levels. Firstly, such a comparison will contribute to the understanding of just what levels of attention different kinds of impact factors ought to have in the pre- and in-service education of mathematics teachers. This is likely to increase the quality of teaching involving practical activities in school mathematics. Secondly, the comparison will contribute to the discussion of what level of reflection that ought to be expected from teachers choosing to use a practical activity.

In order to attempt to classify hierarchically impact factors that influence the teacher's choice of using a practical activity, a system theoretical point of view is used. An alternative theoretical approach could have been a practice theoretical point of view, for instance based on Shulman's (1987) knowledge base for teaching and pedagogical content knowledge. Veal and MaKinster (1999) offer such an approach in their identification and characterization of the relative importance of various components of pedagogical content knowledge. However, a practice theoretical point of view would not provide an opportunity for hierarchical classification, since such a point of view is not hierarchically based (Shulman, 1987). From a system theoretical point of view, it is emphasized that the teacher interacts with several social systems. Thus, the common factor within social system theory is that the teacher is part of a system where he/she influences the totality, and is influenced by this totality (Eide \& Eide, 1996).

The possibility of a rather simplistic, hierarchical categorizing of clusters of impact factors seen through a system theoretical framework opens up for a discussion about extended emphasis on some impact factors compared to others, based on qualitative, empirical data. The research question is: In what way do mathematics teachers' experiences call for an adaptation of a system theory based hierarchy of impact factors regarding the choice of whether to use practical activities in mathematics teaching?

\section{Theoretical background}

The teacher's choice among possible choices and the realization of it depends on how the teacher observes the surroundings. The teacher has to make choices related to his/her highly complex surroundings. When the surroundings are experienced as complex, the experience and reflection based choices made by the teacher will to a large extent be about reducing this complexity (Nordahl, 2007). According to a system theoretical perspective the complexity of the situation may be reduced through an increase in the teacher's sophistication. If the teacher becomes more sophisticated through more knowledge, experience, expectations and so forth, the surroundings will be perceived as less complex (Rasmussen, 2004). Bateson's (1972) hierarchical categorization of learning and communication offers a classic perspective to the teacher's aim of reducing surrounding complexity, through the introduction of levels with increasing complexity. Change on a level will generate change on the lower levels in the hierarchy, and due to the nature of system theory have impact higher up in the hierarchy.

Bateson's theory is based on the assumption that communication between participants establishes and develops relationships, and that the relationships decide how the communication takes place. The 
interactional patterns of the communication make up the structure of the system (Eide \& Eide, 1996). This interaction influences the system and the system influences the interaction. In the essay "The Logical Categories of Learning and Communication" Bateson (1972) links learning to the element of change. Through a logical division in levels of learning and communication, with the levels labelled 0,1 and 2, he suggests that the influence of personal features on learning processes should be organized hierarchically. Actually, Bateson (1972) suggests that the number of levels might continue, but it becomes more and more difficult to see how a higher level of interpretation and change will materialize (e.g. Glosvik, 2000). With regard to learning, Bateson characterizes learning at Level 0 as first-order learning, learning at Level 1 as second-order learning, and so forth. From a teacher perspective, Level 0 then is about receiving, understanding and responding to signals and responses stemming from the teaching experience. The teacher's learning at level 0 will be about developing (more or less) automatic actions (or reactions) based on received signals and responses (Glosvik, 2000). In the example with the use of a leek this will refer to (immediate) feed-back that the practical activity generates and (immediate) adjustments of the teaching based on this feed-back.

Level 1 relates to the way the teacher acts, and is about changing actions to adapt to responses to performed actions from other groups of people in the system constituted around the teacher. Secondorder learning is thereby a revision of actions based on experiences provided by actions at Level 0 , which again generates changes at Level 1 , and consequently at Level 0 due to the influence of change downwards in the hierarchy. In the example this will refer to possible adjustments of the teaching approach, for instance regarding the level of pupils" "hands-on participation" in the investigation process or the teacher's reflections on the conditions for using such an activity.

Level 2 will be influenced by the teacher's internal responses to experiences at Level 1 and consists of factors that control second-order learning at Level 1. Hence, third-order learning is about the teacher's interpretation of new experiences stemming from responses and learning at Level 1, with a subsequent development of alternatives that control changes in learning processes. It can, for instance, be a subconscious change of the teacher's beliefs about how mathematics ought to be taught and learned, and about the teaching conditions necessary for such a change. With reference to the activity involving the leek, the teacher's beliefs about the balance between pupils' participation and acquisition (Sfard, 1998) regarding algebraic deduction can be influenced. This implies a possible impact of the teacher's identity as a teacher, through the influenced balance between what Sfard and Prusak (2005) refer to as the teacher's actual and designated identity. This distinction respectively represents "the actual state of affairs" of the teacher's teaching, and what "for one reason or another is expected to be the case" (Sfard \& Prusak, 2005, p. 18).

\section{A theoretically grounded hierarchy of impact factors}

Some impact factors are considered to be more influential than others, but since the experienced relevance of an impact factor is quite subjective the impact factors that appear to prevail in influencing teaching differ from teacher to teacher. Nevertheless, it is possible to suggest impact at different levels. A three-level hierarchy of factors with impact on the teacher's use of practical activities in mathematics can be seen as parallel to Bateson's hierarchy. In order to provide analogically a hierarchy of impact factors based metaphorically on Bateson's approach, impact factors should be divided into two categories: primary and secondary impact factors. These two categories represent, respectively, impact factors that are teacher related and impact factors stemming from sources external to the teacher. The categories of impact factors are both discrete and intersecting, and hence it may be somewhat indiscriminate to cluster them into only two categories. But a suggestion of a Bateson inspired hierarchy of impact factors does not call for specific identification of a possible impact factor. The hierarchy is merely a categorization of impact factors designed to show how Bateson's hierarchy of learning and communication can be interpreted as applicable for describing the influence and possible 
change of influence of primary and secondary impact factors on teachers' choice to use a practical activity in mathematics teaching.

Secondary impact factors (Level 0) - impact factors from sources external to the teacher

Starting at the ground level of the hierarchy (Level 0), several impact factors stemming from sources external to the teacher influence both the teacher and the teacher's choice of using a practical activity in mathematics teaching (Mosvold, 2005; Frykholm, 1999; Koehler \& Grouws, 1992; Ernest, 1989). The teacher is, to a limited extent, in position to influence impact factors such as populist theories about how mathematics ought to be taught, the official curriculum, structure of the school system, or the physical environment. The teacher is better positioned to respond to other factors stemming from external sources by adjusting the organization of the teaching. Examples of such factors are structuring factors as the number of pupils, access to equipment that makes it possible to use practical activities, or work pressure. There may also be impact factors of a more relational kind, such as recommendations of in-service education in mathematics, suggestions and inspirations from colleagues, comments on teaching by pupils and parents, or the teacher's experiences with time constraints. As all the impact factors stem from sources external to the teacher, and are directed towards the teacher either as guidelines or frameworks for the teaching, or responses to delivered instruction, it is appropriate to cluster them in one category - secondary impact factors.

Primary impact factors (Levels 1 and 2) - impact factors related to the teacher

The teacher's disciplinary knowledge, didactical knowledge, and beliefs about mathematics and its teaching are put forward as crucial parts of the teacher's professional knowledge (Frykholm, 1999; Koehler \& Grouws, 1992; Ernest, 1989; Shulman, 1987). Critical influence on the teacher's planning and teaching stem from these primary impact factors. Such influence is based on responses given to a teacher's teaching and his/her reflections about these responses (Level 1). According to Bateson, change at Level 1 leads to change at Level 0 . Therefore, change in the teacher's disciplinary knowledge, didactical knowledge, or beliefs about mathematics and teaching of mathematics may lead to changes in practice related to responses stemming from secondary impact factors (at Level 0). However, research literature reminds us that any change of practice will be temporary if not anchored in change on a higher hierarchical level of influence (Lloyd, 1999). Therefore, teachers' beliefs need to be influenced in order for teaching to change permanently (Wilson \& Cooney, 2003). Furthermore, attempts to influence teaching practice in a direction that requires a more developed disciplinary and/or didactical knowledge than that already possessed exposes teaching practice to influence from external sources (Haara \& Smith, 2009). This requires the teacher to have developed a profound understanding of the beliefs that have been given prevailing influence, for instance through an intervention process (Haara \& Smith, 2012), and coincides with Bateson's logical necessity of making impact on a higher level in the hierarchy in order for persistent changes to emerge.

A higher level of primary impact factors can also be identified (Level 2). The influence of the teacher's own responses to change depends on the teacher's reflection and self-confidence regarding his/her disciplinary and didactical knowledge and beliefs. Changes at this level may be identified through changes in interpretations and acknowledgement of experiences that the current state of the primary impact factors on Level 1 generates in practice. Such a change could, for instance, be a change in the teacher's beliefs about how mathematics is to be taught. Consequently, this may initiate efforts to make change at Levels 1 and 0. To Bateson (1972), learning at this level can have an impact on one's character. Hence, teacher learning at Level 2 changes the teacher identity (Sfard \& Prusak, 2005; Korthagen, 2004) and the balance between actual and designated teacher identity (Sfard \& Prusak, 2005).

Visualization of a hierarchical structure

Based on the preceding clustering of impact factors, a theoretically grounded hierarchy of impact factors (Figure 1) that influence a teacher's priorities when choosing to use a practical activity in 
mathematics teaching can be suggested. The cluster at level 0 is a bit broader than the clusters at Level 1 and 2 since there are some secondary impact factors that will not be affected by teacher-related impact factors, like for instance the number of pupils in class or the curriculum:
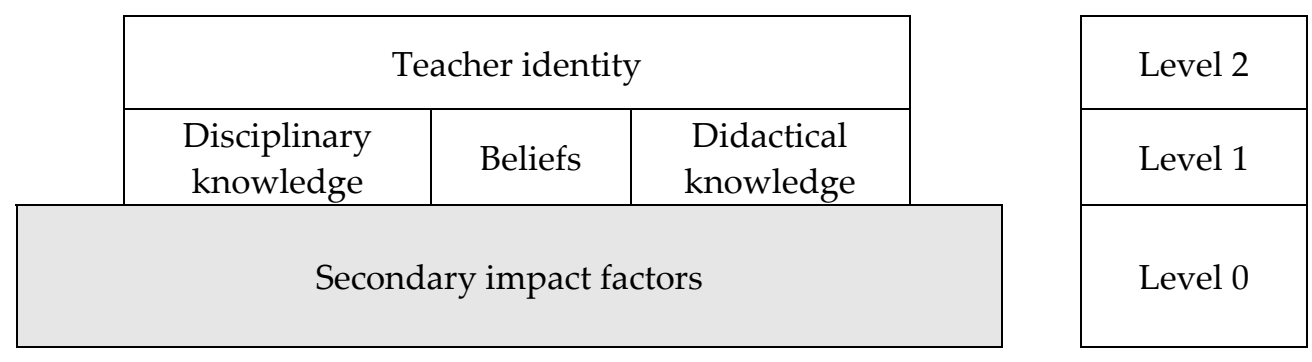

Figure 1. Suggestion of a theoretically grounded hierarchy of impact factors

Regardless of where an impact factor is recognized in this hierarchical structure, the derived impact on teaching practice varies. Hence, studies of the complexity of a specific impact factor and its implications for teachers' choices, like for instance the influence from educational policy on mathematics teachers' development of instructional practices (Cobb \& Jackson, 2012), may lead to various impressions of teachers' experience of the influence of the impact factor in question. However, by keeping the number of levels as low as possible, it is less likely to categorize any impact factor wrongly and one is able to pinpoint the qualitative difference between the origins of primary and secondary impact factors.

\section{The Study}

The implemented study examines ways in which teachers' experiences with impact factors when choosing to use a practical activity in mathematics teaching might call for adjustment of the theoretically grounded hierarchy visualized above. A qualitative approach was chosen to allow mathematics teachers to present their experiences. This provided opportunity for both phenomenographic (Åkerlind, 2005) and hermeneutic (Grønmo, 2004) analysis of the participating teachers' explanations and reasons. Data were produced through response from acknowledged teachers of mathematics to an open questionnaire and structured interviews with two acknowledged teachers of mathematics. In Haara and Smith (2009), acknowledged teachers of mathematics are defined as teachers who are viewed as competent mathematics teachers by the principal and earn respect from colleagues, pupils and other groups of relevance within the working environment. Acknowledged teachers are often expert and/or experienced in the way these terms are defined (Shulman, 1987; Berliner, 1986), but they also add qualities to their positions through the positive impact they are recognized to have on their surroundings. They may, regardless of levels of formal disciplinary or didactical competence, or years of experience, have quite some authority with respect to change or preservation of current directions within their working environment regarding priority of mathematical content and preferred methodology.

\section{Participants}

Thirty Norwegian compulsory schools (pupils aged from 6 till 16 years old) were randomly picked. The selection process was monitored by an independent observer. The principals were contacted, informed about the study and asked to participate by recruiting from the school one teacher recognized by the principal as an acknowledged teacher of mathematics, and who would agree to respond anonymously to an open questionnaire. All the principals agreed to participate in the study, and acknowledged teachers of mathematics were recruited.

In addition, six teachers initially recruited as acknowledged teachers of mathematics for another study on teachers' choice of practical activities (Haara \& Smith, 2009) were asked to respond to the 
questionnaire. The intention was to interview two acknowledged teachers of mathematics about hypotheses formulated on the basis of the analysis of data from the open questionnaire. Therefore, it was seen as important that these two interviewees were familiar with the questionnaire when being interviewed. A random draw of two teachers from this group of teachers would not interfere with the anonymity of teachers recruited by principals, and it would secure interview participation by teachers who had shown on a previous occasion (Haara \& Smith, 2009) that they could handle the interview situation and contribute with high quality reflections.

Each of the thirty recruited principals received an envelope containing the questionnaire, a letter of information to the principal, a letter of information about the questionnaire, and a stamped envelope. The principal was asked to give the questionnaire and the letter of information to the teacher. The teacher returned the completed questionnaire to the principal who then mailed the questionnaire to the researcher. All thirty principals assured that they would do their best to support the study, but eleven (11) schools did not participate, in the end. Hence, twenty-five (25) completed questionnaires ( $70 \%$ response rate) including the questionnaires from the additional six teachers were received, as they had confirmed in advance their agreement to participate in the study. Their anonymity remained the same as that for the other nineteen questionnaires; they were instructed to follow the same mailing procedure as the principals.

The two interviewed teachers (called here Xantippe and Zoltan) were randomly selected among the six teachers, and the selection was approved by an independent observer. Both teachers have worked as mathematics teachers in the Norwegian compulsory school for more than 25 years each, Zoltan mainly in lower secondary school and Xantippe in primary school.

\section{The open questionnaire}

The initial questions of the questionnaire examined the responding teacher's teaching of mathematics and personal definition of what characterizes a practical activity. This was followed by questions enquiring about the influence of primary and secondary impact factors on the teacher's planning and actual teaching, and questions regarding the influence of secondary impact factors on primary impact factors. The last part of the questionnaire contained four questions about demographic facts concerning the teacher's age, formal education, and teaching experience. The questionnaire was validated by three researchers and three experienced teachers of compulsory school mathematics, who read through the questionnaire and commented on the clarity of each question.

The questionnaire produced hand-written answers from the responding teachers. Extractions of meaning of the answers were identified and structured (Grønmo, 2004). A phenomenographic analysis was then applied to sort the extractions into categories of description (Åkerlind, 2005), in the sense that the reproduction of the answers given by the participating teachers should represent the state of affairs in the practice field (Dodd \& Epstein, 2012), and allow both categorizing of perceptions and the idea of hierarchical dimensions, and therefore a potential hierarchy of impact factors (Kvale \& Brinkmann, 2009; Grønmo, 2004). Hence, the analytic approach was chosen to bring forward the participants' own impressions and interpretations of their experiences. The analysis showed that in addition to impact factors already labelled as primary or secondary, the teachers put emphasis on some impact factors that are neither solely primary nor solely secondary impact factors. They should rather be labelled as primary impact factors depending on responses from secondary impact factors. Three such impact factors were identified: the teacher's everyday life experiences, the teacher's knowledge about the everyday life of pupils, and the teacher's conscience, where conscience refers to the inner feeling that acts as a guide to the rightness or wrongness of one's behaviour. 


\section{Interviews}

Each interview consisted of four clusters of questions. First there was a cluster of questions regarding the influence of impact factors related to the teacher's use of practical activities. The main part of the interviews then consisted of three clusters of questions, each with regard to one of three hypotheses based on the results from the analysis of answers from the questionnaires:

- The teacher's everyday life experiences influence the frequency of possibilities for using practical activities in mathematics teaching.

- The teacher's knowledge about pupils' everyday life experiences influences the frequency of possibilities for using practical activities in mathematics teaching.

- The teacher's use of practical activities is related to the teacher's conscience.

The structured interview was piloted with a teacher from the remaining group of four teachers not selected for interview.

The interviews were fully transcribed. First a holistic impression of the material was established. Then sequences were identified and themed in accordance with the holistic impression of the informants' answers in order to describe the situation in the practice field (Dodd \& Epstein, 2012), and seen in relation to the suggested hypotheses. The sequences were analyzed through a thematic content analysis, in order to find points of validation or falsification of the proposed hypotheses (Kvale \& Brinkmann, 2009). Finally, a hermeneutical approach was applied in a holistic analysis of the data from both empirical sources, seen in relation to the influence of impact factors when choosing to use a practical activity in mathematics teaching (Grønmo, 2004). This increased the viability of the first interpretations made of data from the questionnaires. Hence, the second round of analysis strengthened the viability of the hypotheses formulated from the analysis of the questionnaires. Figure 2 illustrates the design of the study:

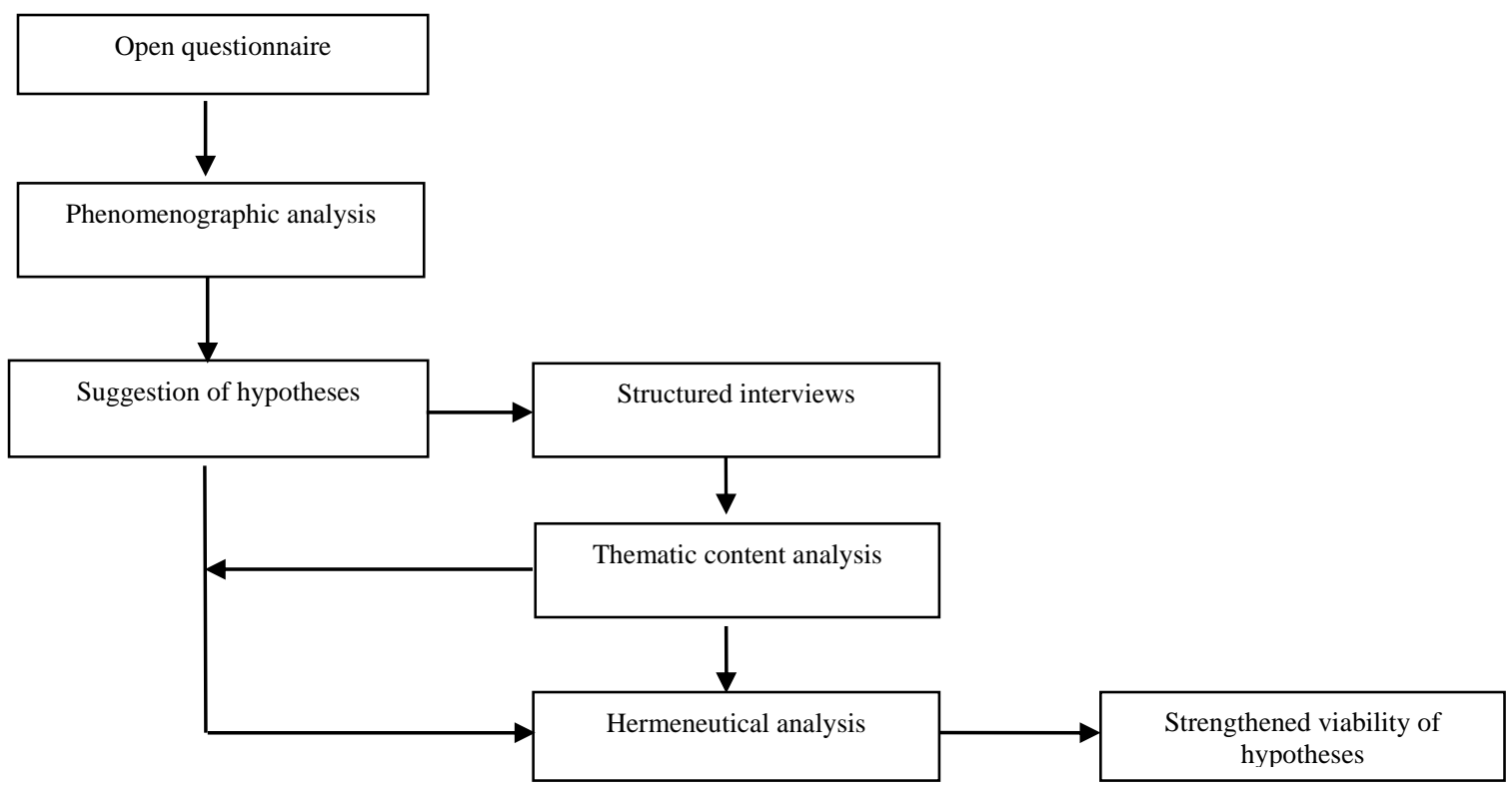

Figure 2. Study design

\section{Findings}

The attempt to distinguish between primary and secondary impact factors implies a rigid bilateral classification of identified impact factors. The collected data confirm that mathematics teachers associate several distinct impact factors with influence on use of practical activities in mathematics teaching, and that the experienced influence from an impact factor is individually weighted by each 
teacher, regardless of the categorization of that impact factor as primary or secondary. The following two utterances given by two teachers in the questionnaire illustrate this interpretation (The teachers are given a label (Teacher $\mathrm{X}$, where $\mathrm{X}$ is a number) when they first are quoted in the article. If a teacher is quoted several times he/she keeps the label from the first quote):

Teacher 1: Resources, materials, time + the number of teachers present. This might on occasion limit my use of practical activities.

Teacher 2: As I have a broad disciplinary knowledge in mathematics, it is always easy to use practical activities in teaching. You have to be disciplinary confident to rely on practical activities.

It is therefore not possible to compare an isolated experience of the influence of an impact factor to a hierarchical clustering of impact factors. This impression was confirmed by Zoltan and Xantippe through the interviews in, for example, the following:

Xantippe: As a teacher I am facing great expectations. I am responsible to my superiors ... I am supposed to work towards measurable aims [given through the national curriculum]. Hence, I cannot leave out anything, because then I would not be doing my job. But then it is up to me to find ways of teaching ... if one wants to do practical activities, I do not see any problems in doing so, but I do have to make a plan [for the teaching] ...

Zoltan: A factor which I have to consider when it comes to practical applications ... is time. There are activities, I have to admit, that ... I choose not to include in the teaching .... My experience says that the effect of some activities in proportion to the required time makes it difficult for me to defend any use of them.

The data from the questionnaire did not challenge Bateson's idea of the necessity of influencing primary impact factors (Level 1) for changes to occur regarding the influence of secondary impact factors (Level 0) as a hierarchical consequence. The two interviewed teachers rather confirmed than discounted this through specific emphasis on the importance of primary impact factors when deciding to use or not to use a practical activity:

Xantippe: ... [related to an example from a lesson outdoor on a windy day in which paper planes were made from folded A4-sheets] ... it is about seizing the opportunity, right? One should not have everything planned before the lesson ... but have the opportunity to see that ... Wow! They [the planes] went straight up, and then backwards ... may we then introduce negative numbers? You cannot be too caught up in the plans you have made...

Zoltan: My experiences from years of teaching ... dictate my decision of using a practical activity or not ... in situations in which I see possibilities to do so and so...

Once again the relation to Bateson's interpretation of second-order learning is visible. Primary impact factor revisions are made based on experiences "with variations in the terrain".

The attention can now be turned to the three hypotheses proposed on the basis of the analysis of the data from the questionnaires, and their position and influence in the suggested hierarchical visualization.

Influence from the teacher's everyday life experiences

Data from the questionnaires indicate that teachers look, among available sources, to their personal experiences and interests for examples or activities by which to introduce mathematical content. One teacher (Teacher 3) saw numerous possibilities to combine his experiences from farming with mathematical topics, while another teacher (Teacher 4) stated that it is easy to use personal everyday life experiences: 
Teacher 3: I am also a farmer, and as a farmer, I apply practical mathematics fully. Today, many children do not participate in many such practical activities that are related to mathematics (digging ditches, carpentry, butchering, carrying water and firewood, and so forth).

Teacher 4: It is easy to use personal experiences as examples when relating theory to everyday life, and thereby create a greater understanding for "why we need math".

In the interview, Zoltan focused on his interest in carpentry as a highly valued area for making relevant connections to the organizing of practical activities and to integrate mathematical theory and application. He was clear about the possibilities that were revealed in prioritizing his everyday experiences from house building and arts and crafts:

Zoltan: ... I actually use woodwork and carpentry on occasions. That is, I introduce old-fashioned carpentry to apply working drawings, and integrate mathematics in the work we do. And that is something that the pupils appreciate. We work with scales and other geometrical topics through an approach that is completely different from the theoretical approach we apply in the mathematics classroom.

Xantippe, on the other hand, was slightly more restrained regarding the possible influence of the teacher's everyday life experiences. She pointed out that it should not be required to have a specialized or rich level of experiences outside school to be a qualified mathematics teacher:

Xantippe: I can see the point in having a hobby or a profession outside school, something that can be appropriate to bring into teaching, but it is not crucial. I do not see that teaching requires having ... to do something special in your spare time to bring it into teaching. You can find topics and other stuff as well!

Influence from the teacher's knowledge about the pupils' everyday life experiences

Responses to the questionnaires show that the teacher's knowledge about pupils' everyday experience is recognized as an influential resource for the teacher. This counts in a teacher's efforts to get to know each pupil, and in this particular case, when relating mathematical content to practical situations and activities relevant to pupils' experiences outside school:

Teacher 5: [In answer to a question about how the teacher experiences his/her didactical knowledge as influencing the choice to use a practical activity in the teaching] ... I encourage pupils to solve the problems and to choose the approach to each problem themselves. They get to use their everyday experiences.

Both Xantippe and Zoltan confirm the importance of the teacher's knowledge about pupils' everyday life experiences:

Xantippe: To me pupils' everyday life experiences are almost more important than anything, really. That we feel that they develop an ownership of what they do, because it is familiar to them.

Zoltan: ... the most important thing you can achieve in mathematics teaching, I would say, would be if the pupils could bring their everyday lives, their practical experience, into the mathematics class.

\section{Influence from the teacher's conscience}

Data from the questionnaires indicates that a conscious realization of preventive features of using activities is a recurrent theme, especially in terms of the influence of the effects of ever-present dilemmas related to time constraints:

Teacher 6: I experience several factors that prevent the use of practical activities; for instance, allocation of substitute teacher lessons, a lot of papers to mark, and little time for preparation.

Teacher 7: A lot of factors have to be taken into consideration regarding the choice to use a practical activity. But the most important is, by far, time. Practical activities take time. The pupils are supposed to go through a huge quantity of mathematical content .... You do the math. 
Zoltan and Xantippe also recognize this dilemma as an influencing impact factor that is frequently present when setting their mathematics teaching priorities:

Xantippe: ... it was not so easy to do really, teaching a mathematics lesson outside. Maybe we as teachers had too little experience, so that ... you had maybe just two pupils with you and the rest of the class was pretending to be Indians in the woods ....

Zoltan: I never have a good conscience, because it is always something that you should have done, but that you cannot do. If you use a lot of practical activities ... I have done that sometimes, and I have thought that now I am really going to ... and then I have arranged for a project, and spent much time on it, and then I have often felt that, Oh, my goodness! Did this produce any results at all? ... the conscience rebounds that way! So you constantly experience dilemmas, it is part of the job.

Following his indication of this dilemma, in relation to the impact of conscience, Zoltan continues by pointing to primary impact factors as an important counter weight against influence stemming from secondary impact factors such as time constraints. When time constraints prevent a practical activity, a secondary impact factor opposes the primary value-based impact factor that the teacher sees in the practical activity. The tension arising from the contradiction, between the experienced time constraints at Level 0 in the hierarchy of impact factors and the Level 1 based wish to use a practical activity, emerges as guilty conscience. Hence, the influence of primary impact factors is necessary for dealing with both dilemmas and the considerable conscience challenges that may arise from choices made in the face of dilemmas about whether to use a practical activity or not:

Zoltan: ...in a way I feel that there are nuances related to being a very professionally confident mathematics teacher ... that is, I think that conscience, it can become intolerable, almost detrimental, if you are a mathematics teacher who is not disciplinary or didactically confident, because ... I have experienced these dilemmas myself, that you can have a guilty conscience no matter what you do ... but this only gets worse if you are disciplinary or didactically unconfident. Then you will almost develop a guilty conscience no matter what. You will, probably, if you use a lot of practical activities ... you have been to courses and you have heard that it is the right thing to do ... and then you do it, and realize that you are losing time, and feel badly about that ... because you believe that you have done much wrong .... Or you can choose to keep up a steady pace getting through the whole textbook, and you cannot do [practical activities] ... and then you get a guilty conscience because of that. So I feel that disciplinary and didactical overview is extremely important in mathematics. In a way it is not enough to master what is presented in the textbook ....

Zoltan describes a situation that suggests that the teacher's conscience is influenced by both primary and secondary impact factors, and that conscience as an impact factor leads to responses that influence both primary and secondary impact factors.

\section{Discussion}

The findings confirm that teachers' everyday life experiences, their knowledge about pupils' everyday life experiences, and their conscience are impact factors with potential influence when it comes to choosing to use practical activities in mathematics teaching. Furthermore, according to the definition of impact factor and the classification of primary and secondary impact factors they should not be treated solely as primary or secondary impact factors. They are based on the teacher's knowledge and beliefs, but are at the same time dependent on secondary impact factors, such as for instance, pupils' qualifications and interests, time constraints, and curriculum demands. Hence, it seems necessary to make an expansion of the Batesonian inspired hierarchy based on teacher experience (Figure 3): 

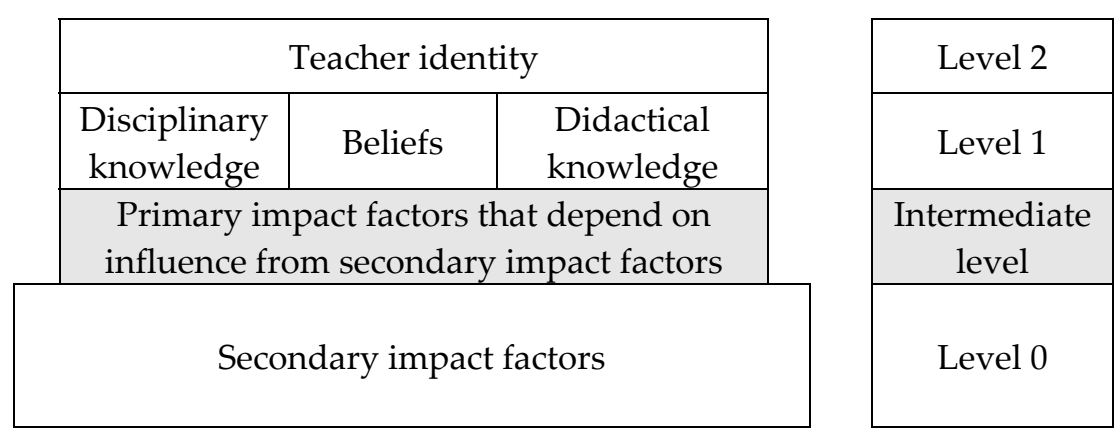

Figure 3. An expansion of the suggested hierarchy of impact factors

The intermediate level would require the same width as Levels 1 and 2 in the hierarchy, since some secondary impact factors are not affected by teacher-related impact factors, as mentioned earlier. Conversely, the introduction of an intermediate level in the hierarchy would obfuscate the thought of aligning a Bateson inspired hierarchy of clusters of impact factors and teacher learning, if the added level would require a separate order of learning. But since they are interpreted as primary impact factors that depend on influence from secondary impact factors both first- and second-order learning would in that case be recognizable.

The importance of the teacher's everyday life experience is a form of tacit teacher knowledge that to some extent has been overlooked when reviewing and suggesting models for teachers' knowledge (e.g. Fennema \& Franke, 1992; Koehler \& Grouws, 1992). The focus has been mainly on disciplinary and didactical knowledge components, in addition to teacher beliefs (Philipp, 2007). Gudmundsdottir and Shulman (1987), on the other hand, call attention to the impact of the teacher's knowledge of topics that pupils find interesting, as an example of pedagogical content knowledge influenced by knowledge about the students. For teachers with a developed professional knowledge in mathematics, everyday life experiences may represent a rich source of relevant situations and examples for teaching mathematics through practical activities. This might be the case for both the teacher's everyday life experiences and the teacher's knowledge about pupils' everyday life experiences, although these impact factors might influence instructional decisions in different ways. This is one of the possible responses to the aim of more focus on mathematical literacy in school mathematics (OECD, 2013; De Lange, 2003). When it comes to what influences the choice to use a practical activity, the teacher's main attention must be on the pupils' perceptions of what is being taught. If the teacher refers to something pupils do not recognize or find interesting, the practical activity, for motivational reasons, will probably not generate the teacher's intended impression and effect. According to Xantippe, the teacher's attention to pupils' everyday experiences is a more important resource than the teacher's personal everyday experience. Pupils' experiences ought to prevail when it comes to what issues to emphasize when choosing to use a practical activity in mathematics teaching. At the same time this should not prevent the teacher from introducing mathematics through practical activities based on experiences with which the pupils are unfamiliar. After all, it is the school's responsibility to provide the pupils with knowledge and skills relevant to life (OECD, 2013; De Lange, 2003). This calls for introduction of themes still unfamiliar to the pupils.

The teacher's conscience is an impact factor that seems to be influential in the teacher's choice to use a practical activity, and it is an impact factor that in research literature on occasions are referred to as "having a guilty conscience" (e.g. Frykholm, 1999; Mellin-Olsen, 1996). In this study, answers to the questionnaire, and Zoltan when asked about the influence of his conscience, attach conscience considerations to the tensions that teachers experience when they are confronted with decision dilemmas (Mellin-Olsen, 1996; Lave, 1988). Zoltan suggests that a possible way of trying to handle the influence of conscience is for the teacher to change his/her primary impact factors, by further development of disciplinary and/or didactical knowledge. Seen in relation to the suggested hierarchal 
structure of impact factors, this is followed by changed influence from secondary impact factors. Such a process would mean that the teacher's experiences with practical activities in mathematics teaching are systematically used to adjust the foundation for teaching by changes on a higher level in the hierarchy. Changes made by the teacher based on his/her guilty conscience, however, would be made without making an impact on Level 1 . The changes will be merely adjustment activities within unchanged conditions, according to Glosvik's (2000) description of adjustment activities in a Batesonian understanding of learning processes.

\section{Conclusions}

The aim of this article has been three-sided. First, I wanted to suggest a theoretically grounded hierarchical classification of impact factors that influence a mathematics teacher's priorities when choosing to use a practical activity. Second, I wanted to identify possible discrepancies between the suggested hierarchy and experiences of mathematics teachers, through the voices of acknowledged teachers of mathematics. And last, but not least, it was intended to examine and discuss ways in which teachers' experiences might call for an adjustment of the suggested hierarchy. Responses from teachers were given through open questionnaires and structured interviews. The teachers' responses to the questionnaire led to three hypotheses regarding impact factors that did not fit the suggested hierarchical classification. The analysis of structured interviews with two teachers supported the hypotheses. This strengthened the viability of the hypotheses, although without producing anything else than support to the necessity of attention to these three impact factors in a hierarchy of impact factors.

In spite of the limitations of this study, it confirms that clusters of impact factors influencing teachers' choices to use practical activities can be organized in a hierarchical structure. Furthermore, I acknowledge that changes ought to occur on a higher level in a hierarchy of impact factors in order for the teacher to develop further the reasons for choosing to use practical activities in mathematics teaching. This is in accordance with a Batesonian hierarchical structure about learning. But, such a binary clustering of impact factors probably does not treat all kinds of impact factors properly. The teacher's everyday life experience, the teacher's knowledge of pupils' everyday experiences, and the teacher's conscience seem to be examples of impact factors related to the teacher's use of practical activities that are capable of having an impact on whether the teacher decides to use a practical activity or not. These impact factors should not be categorized solely as primary or secondary impact factors. The influence of the teacher's everyday life experiences and the teacher's knowledge of the pupils' everyday life experiences are, on the one hand based on the teacher's beliefs and knowledge, and on the other hand dependent on relations between teacher and pupils. The influence of the teacher's conscience is related to beliefs and knowledge, but it is also dependent on how much the teacher lets secondary impact factors, such as time constraints or curriculum demands, influence the teaching. Hence, a model based on a Batesonian hierarchy of learning and communication does not completely satisfy the experience-based impressions of impact factors that influence the teacher's choice of practical activities. The incorporation of an intermediate level of impact factors in the hierarchy would be required, and calls for a more complex visualized structure of impact factors.

In this article attention has been drawn to three impact factors located at what would be an intermediate level of an established system theory based hierarchy classification attempt. The influence of each of these impact factors should be examined individually, and in larger and more longitudinal studies to establish more thoroughly their influence on teachers' use of practical activities in mathematics teaching and in order to suggest a more complex and proper model for influence from impact factors on teachers' choice of using practical activities. In the classroom of the mathematics teacher, the hierarchy suggestion presented in Figure 2 may hopefully lead to a better understanding of classroom practice when choosing to use practical activities in mathematics teaching, the influence 
of impact factors and what to prioritize in order to strengthen the development of mathematical literacy in school mathematics (OECD, 2013; OECD, 2009; Blum, Galbraith, Henn \& Niss 2007; De Lange, 2003), and more space and independence for the teacher when planning and teaching mathematics in school (Haara, 2011).

\section{References}

Bateson, G. (1972). The Logical Categories of Learning and Communication. In G. Bateson, Steps to an Ecology of Mind (pp. 279308). Chicago: The University of Chicago Press.

Berliner, D. C. (1986). In Pursuit of the Expert Pedagogue, Educational Researcher, 15(7), 5-13.

Blum, W., Galbraith, P. L., Henn, H.-W. \& Niss, M. (Eds.) (2007). Modelling and Applications in Mathematics Education. The 14th ICMI Study. New York: Springer, New ICMI Studies series 10.

Cobb, P., \& Jackson, K. (2012). Analyzing educational policies: A learning design perspective. The Journal of the Learning Sciences, 21(4), 487-521.

De Lange, J. (2003). Mathematics for Literacy. In B.L. Madison \& L.A. Steen (Eds.), Quantitative Literacy. Why Numeracy Matters for Schools and Colleges (pp. 75-89). Princeton, NJ: The National Council on Education and the Disciplines.

Dodd, S.J. \& Epstein, I. (2012). Practice-Based research in social work. A guide for reluctant research. New York: Routledge.

Eide, H., \& Eide, T. (1996). Kommunikasjon i relasjoner. Samhandling, konfliktløsning, etikk [Communication in relations. Interaction, conflict resolution, ethics; in Norwegian]. Oslo: Ad Notam Gyldendal.

Ernest, P. (1989). The Impact of Beliefs on the Teaching of Mathematics, In P. Ernest (Ed.), Mathematics Teaching: The State of the Art (pp. 249-254). London: Falmer Press.

Fennema, E., \& Franke, M. L. (1992). Teachers' Knowledge and Its Impact. In D. A. Grouws (Ed.), Handbook of Research on Mathematics Teaching and Learning (pp. 147-164). New York: Macmillan.

Franke, M. L., Kazemi, E. \& Battey, D. (2007). Mathematics Teaching and Classroom Practice. In F.Lester (Ed.), Second Handbook of Research on Mathematics Teaching and Learning (pp. 225-256). Charlotte: Information Age Publishing.

Frykholm, J. A. (1999). The Impact of Reform: Challenges for Mathematics Teacher Preparation. Journal of Mathematics Teacher Education, 2(1), 79-105.

Glosvik, Ø. (2000). I Grenselandet-læring mellom stat og kommune [In the Border area-learning between state and municipality; in Norwegian]. (doctoral dissertation). Bergen: University of Bergen.

Grønmo, S. (2004). Samfunnsvitenskapelige metoder [Methods in social science; in Norwegian]. Bergen: Fagbokforlaget.

Gudmundsdottir, S., \& Shulman, L. (1987). Pedagogical Content Knowledge in Social Studies. Scandinavian Journal of Educational Research, 31(2), 59-70.

Haara, F. O. (2011). Unveiling teachers' reasons for choosing practical activities in mathematics teaching. (doctoral dissertation). Bergen: University of Bergen.

Haara, F. O. (2003). Frukt og grønt til utforsking og konkretisering i geometri [Fruit and vegetables for exploring and concretizing in geometry; in Norwegian], Tangenten, 14(1), 29-32.

Haara, F. O., \& Smith, K. (2009). Practical activities in mathematics teaching-mathematics teachers' knowledge based reasons. Nordic Studies in Mathematics Education, 14(3), 33 -54.

Haara, F. O., \& Smith, K. (2012). Increasing the Use of Practical Activities through Changed Practice. The Mathematics Enthusiast. $9(1 \& 2), 77-110$.

Handal, G., \& Lauvås, P. (1987). Promoting Reflective Teaching: Supervision in action. Milton Keynes: Open University Educational Enterprises Ltd.

Kjærnsli, M., Lie, S., Olsen, R. V., Roe, A., \& Turmo, A. (2004). Rett spor eller ville veier? Norske elevers prestasjoner i matematikk, naturfag og lesing i PISA 2003 [Right track or wrong direction? The achievements of Norwegian pupils in mathematics, science and reading in PISA 2003; in Norwegian]. Oslo: Universitetsforlaget.

Klette, K. (Ed.). (2003). Klasserommets praksisformer etter reform 97 [The practice styles of the classroom after reform 97; in Norwegian]. Oslo: Pedagogisk forskingsinstitutt.

Koehler, M. S., \& Grouws, D. A. (1992). Mathematics Teaching Practices and Their Effects. In D. A. Grouws (Ed.), Handbook of Research on Mathematics Teaching and Learning (pp. 115-126). New York: Macmillan.

Korthagen, F. A. J. (2004). In search of the essence of a good teacher: towards a more holistic approach in teacher education, Teacher and Teacher Education, 20(1), 77-97.

Kvale, S., \& Brinkmann, S. (2009). Det kvalitative forskningsintervju. [The Qualitative Research Interview; in Norwegian]. Oslo: Gyldendal Norsk Forlag AS.

Lave, J. (1988). Cognition in Practice. Cambridge: Cambridge University Press.

Lloyd, G. M. (1999). Two Teachers' Conceptions of a Reform-oriented Curriculum: Implications for Mathematics Teacher Development, Journal of Mathematics Teacher Education, 2(3), 227-252.

McNeil, N. M., Uttal, D. H., Jarvin, L., \& Sternberg, R. J. (2009). Should you show me the money? Concrete objects both hurt and help performance on mathematics problems. Learning and Instruction, 19, 171-184.

Mellin-Olsen, S. (1996). Oppgavediskursen i matematikk [The discourse of tasks in mathematics; in Norwegian]. Tangenten, 7(2), 9-15.

Mosvold, R. (2005). Mathematics in everyday life. A study of beliefs and actions. (doctoral dissertation). Bergen: University of Bergen.

Moyer, P. S. (2001). Are we having fun yet? How teachers use manipulatives to teach mathematics. Educational Studies in Mathematics, 47(2), 175-197. 
Myklebust, T. (1994). Arealet til sirkelen og integralrekning i ungdomsskulen [The area of the circle and integral calculus in lower secondary school; in Norwegian]. Tangenten, 5(3), 10-12.

Nordahl, T. (2007). Undervisningens kompleksitet og lærerens valgmuligheter [The complexity of teaching and the teacher's options; in Norwegian]. In G. Dalhaug \& K. Nes (Eds.), Kompetanse for tilpasset opplering [Competence for adapted education; in Norwegian] (pp. 55-68). Oslo: Utdanningsdirektoratet.

OECD (2009). PISA 2009 Assessment Framework. Key competencies in reading, mathematics and science http://www.oecd.org/pisa/pisaproducts/44455820.pdf

OECD (2013). OECD Skills Outlook 2013. First Results from the Survey of Adult Skills. OECD publishing.http://skills.oecd.org/OECD_Skills_Outlook_2013.pdf

Philipp, R. A. (2007). Mathematics Teachers' Beliefs and Affect. In F. Lester Jr. (Ed.), Second Handbook of Research on Mathematics Teaching and Learning (pp. 257-315). Charlotte, NC: Information Age Publishing.

Rasmussen, J. (2004). Undervisning i det refleksivt moderne: politik, profession, pædagogik [Teaching of the reflexively modern: politics, profession, pedagogic; in Danish]. Copenhagen: Reitzel forlag.

Sfard, A. (1998). On two metaphors for learning and the danger of choosing just one. Educational Researcher, 27(2), 4-13.

Sfard, A., \& Prusak, A. (2005). Telling identities: in search of an analytic tool for investigating learning as a culturally shaped activity. Educational Researcher, 34(4), 14-22.

Shulman, L. (1987). Knowledge and Teaching: Foundations of the New Reform. Harvard Educational Review, 57(1), 1-22.

Veal W. R. \& MaKinster, J. G. (1999). Pedagogical Content Knowledge Taxonomies, Electronic Journal of Science Education, 3(4). Retrieved from: http://ejse.southwestern.edu/article/viewArticle/7615/5382

Wilson, M., \& Cooney, T. (2003). Mathematics Teacher Change and Development: The Role of Beliefs. In G. C. Leder, E. Pehkonen \& G. Törner (Eds.), Beliefs: A Hidden Variable in Mathematics Education?. (pp.127-147). Seacaucus, NJ: Kluwer Academic Publishers.

Åkerlind, G. (2005). Variation and commonality in phenomenographic research methods. Higher Education Research $\mathcal{E}$ Development, 24(4), 321-334. 